\title{
Using storytelling in teaching English in Palestinian schools: perceptions and difficulties
}

\author{
Awad Sulaiman Keshta \\ College of Education, The Islamic University of Gaza (IUG), Palestine
}

Email address:

Dr.awadk@yahoo.com (A. S. Keshta)

To cite this article:

Awad Sulaiman Keshta. Using Storytelling in Teaching English in Palestinian Schools: Perceptions and Difficulties, Education Journal. Vol. 2, No. 2, 2013, pp. 16-26. doi: 10.11648/j.edu.20130202.11

\begin{abstract}
This study aimed at investigating the use of storytelling technique in teaching English in Palestinian Public and UNRWA schools from the teachers' perspectives and the difficulties facing the teachers. To achieve the aim of the study, the researcher conducted an interview consisting of five questions. The sample of the study consisted of 60 teachers. The interview was conducted on the sample of the study inquiring about their gender, qualifications (diploma, BA, M.ED), institution (UNRWA, Public schools) and period of teacher's experience (from 1-5 years, from 5- 10 years, up to 10 years). The study findings revealed that teachers, regardless the previous variables, don't know the exact definition of the storytelling technique. In addition, they use this technique SOMETIMES. Moreover, most of them see that this technique makes students happy and get them memorize the story being taught. Finally, $90 \%$ of the teachers find that this technique is difficult to use, needs time to be applied and causes noise. In light of the study results, the researcher recommends that education stakeholders should train teachers on the use of this technique because it is an important technique to get students memorize the lesson being taught and it also attracts students' attention, and it improves their prediction skills.
\end{abstract}

Keywords: Education, Storytelling, Teaching English

\section{Introduction}

Everyday communication involves telling, listening, and responding to stories. Storytelling has evolved throughout history. The first stories were told through pictures on walls. Then, stories were passed down orally from generation to generation. Storytelling is a means of expressing experiences, emotions and ideas in different forms of transfer and dating back to ancient times Despite all the modern innovations, the attraction of the art of storytelling has not really been lost, particularly, in the field of education where it still carries a major importance. This method, which has become a developed tool in imparting ideas and skills with the aid of the mass media, has become significant in all areas of studies. Storytelling is the art of portraying real or fictitious events in words, images, and sounds. Stories are told for entertainment purposes, and often to teach lessons and provide morals. Storytelling is often considered to be a crucial aspect of humanity. Storytelling is an ancient art that strengthens and enhances skills that children need to acquire to function in today's world.

Statement of the Problem

Palestinian students complain about being unable to use
English efficiently and fully comprehending what they read or listen to. The researcher also noticed that most students get low marks in the English exams at the UNRWA and public schools. The researcher investigates the use of storytelling technique by teachers in public schools in Gaza Governorates. The researcher believes that storytelling which is neglected by the teacher may have a significant role in helping students improve their skills so as to use English efficiently.

\section{Research Questions}

In the light of the study problem, the following two questions emerged:

1- What are the teachers' perceptions of storytelling technique in teaching English in Palestine?

2- What are the difficulties facing English language teachers in using storytelling technique?

\section{The Purpose of the Study}

The current study aimed at investigating the use of storytelling technique in teaching English in Palestinian 
UNRWA and Public schools from the teachers' perspectives and the difficulties facing the teachers.

\subsection{What are Stories?}

Maynard(2005:1) defines stories as the way people communicate their experience, the way they understand the experience of others, the way they liberate their imaginations, the way they make sense of the world and their own position within it. He stated that stories are important to people, politics, and education. Stories are how people make sense of themselves and their worlds. A story tends to have more depth than a simple example. A story tells about some event - some particular individuals, and something that happens to them. Stories engage our thinking, our emotions, and can even lead to the creation of mental imagery (Green \& Brock, 2000).

Green(2004) adds that stories can serve multiple functions in the classroom, including sparking student interest, aiding the flow of lectures, making material memorable, overcoming student resistance or anxiety, and building rapport between the instructor and the students, or among students themselves.

\subsection{Definition of Storytelling}

Storytelling is uniquely a human experience that enables us to convey, through the language of words, aspects of ourselves and others, and the worlds, real or imagined, that we inhabit. Stories enable us to come to know these worlds and our place in them given that we are all, to some degree, constituted by stories: Stories about ourselves, our families, friends and colleagues, our communities, our cultures, our place in history. McDrury and Alterio (2003:30).

Storytelling is a great way how to encourage young learners of English language to be actively participated in the process of learning a foreign language. Storiesprovide the things that are familiar to children and therefore storytelling is a useful way how to introduce new things in the context which is well-known for children. If there is a topic which is hard to explain to children we can integrate the topic to a story. This particular example of the topic, the introduction and solution of the problem might help children to visualise the problem and understand the topic better. Brno (2011)

Barzaq ( 2009: 7) defined storytelling as a knowledge management technique, a way of distributing information , targeted to audiences and a sense of information, she added that stories provide natural connection between events and concepts and finally, she added that visual storytelling is away of telling stories through images.

" Telling is the live, person to person oral and physical presentation of a story to an audience

"Telling" involves direct contact between teller and listener. It mandates the direct presentation of the story by the teller. The teller's role is to prepare and present the necessary language, vocalization, and physically to effectively and efficiently communicate the images of a story " (Barzaq

\section{9:7)}

She emphasized that the listener's role is to create a vital images, actions , characters, and events. The story in the listeners' minds based on the teller's performance. Additionally , she cited in (Egan,1995:116-125) that storytelling is a linguistic activity that is educative because it allows the listeners to share their personal understanding to other people and that it is a performance art that has been revitalized in recent years, and in these days storytellers perform texts that listeners have learned it from books.

\subsection{Origins of Storytelling}

According to Pellowski (1990), there are seven prominent theories towards an origin of storytelling based on research conducted across the disciplines including anthropologists, archeologists. folklorists, philologists, semioticians, linguistics and the discipline of literature. They are as follows:

1) That it grew out of playful, self-entertainment needs of humans; 2) That it satisfied the need to explain the surrounding physical world; 3 ) That it came about because of an intrinsic religious need in humans to honor or propitiate the supernatural force(s) believed to be present in the world; 4) That it evolved from the human need to communicate experience to other humans; 5) That it fulfilled an aesthetic need for beauty, regularity, and form through expressive language and music and body movement; 6) That it stemmed form the desire to record the actions or qualities of one's ancestors or leaders, in the hope that this would give them a kind of immorality; and 7) That it encoded and preserved the norms of social interaction that a given society lived by.

\subsection{Using Storytelling for Educational Purposes}

Traditional versus Modern In traditional social culture, stories weren't only(addressed) to a few people but to a large audience(Güney, 1971). The stories included heroic acts, and legends which united people (Karweik, 1999). They expressed stories about today, yesterday and tomorrow and expressed realities powerfully and thus they explained how a person perceived the outside world. According to Riesman, from the era of Homerous to our present time, people who listen to these stories and people who live in similar places become one.

Storytelling provides an opportunity for students to expand their vocabulary as they decode the meaning of words, based on the context of the story they hear or read. Listening to stories also improves a students' understanding of grammar and literary devices as they see them within a story (Wojciechowicz, 2003).

Storytelling is a unique method of communication and students express their thoughts and ideas in their own unique ways. As students prepare their stories and go through the writing process, it provides them with opportunities for social interaction and an opportunity for self-expression(Craig et al., 2001). Storytelling is not only used for communication purposes, but storytelling has been 
used to teach literacy skills, cooperative learning skills, critical thinking, and to build knowledge of different contexts (Mello, 2001). When students develop reading and writing skills, teachers are able to use storytelling in a written form to teach and convey meanings with students. Much of the traditional literature used in schools has evolved from folk tales and oral stories that were edited and published to teach and convey messages about a culture (Mello, 2001).

storytelling became the domain of librarians and was thus traditionally situated within a story hour. Seen as having more of an entertainment than education value and combined with fears that students were not getting the skills needed to compete for jobs, storytelling never found a foothold outside of the kindergarten classroom. Reilly (2007)

Parr and Campbell(2007:19) state that storytelling is a powerful tool to improve students' writing because it provides "opportunities to identify important details and dialogue, understand and recall stories and story elements, and practice oral language skills such as vocal expression and exaggeration.

Story telling is a means, of creative expressions which are still important nowadays. By using this method, educational subjects can be taught, transferred and developed. Through mass media, storytelling is being done in a variety of ways. It has no limits because it is applicable to every branch of science with interactive tools. Changing roles and ways of interaction in storytelling through various media introduce a new scope of understanding and use of that art. No matter how we tell our stories, it is the content of the message conveyed through different channels and forms which counts.

Belmonte and Verdugo (2007) state that, at an early stage of language acquisition, stories can be a valuable way of contextualizing and introducing new language, they can also make new language meaningful and memorable to the learners. In the same concern, (Niemann, 2003) reports that, with stories children have an access to literature and culture that otherwise they would not get.

\subsection{The Effects of Storytelling on Kids and Adults}

Shelly(2010: 1-2) claimed that reading stories to one's kids is a crucially important part of his or her job as a parent. As a baby and toddler, the little one is picking up language skills at a phenomenal rate. She added that reading stories to young people helps them to increase their vocabulary, understand the parts of language, and learn the rules of English. There is nothing else one can do that has more of an impact on the child's future ability to read and learn than a daily story time. Finally she recommended at least thirty minutes a day of reading stories together even with children. One may conclude that stories affected the listeners either adult or kids by teaching them the language; the structure, new vocabulary, the grammar, and to help the children to think about different new ideas. When one points to objects and name them, his or her toddler can quickly learn to identify many more objects than s/he can verbalize. She asked any parent to ask his or her pre-verbal little one to point to the ball or shoe and the parent will be amazed at how much he can comprehend, even before s/he can speak. As one 's child grows, story time becomes a bonding, connected time that his or her child can count on. The emotional security that can grow from taking the time to sit down and read together is truly priceless. It lets the child know first that s/he is important to her or his parents and second, that reading and learning are fun. And by pointing to the words on the page as the parent read, s/he is helping the child learning to recognize words. Before the parent knows it, the child will be sight reading several words just because the child has had the repetition of hearing the word and seeing it on the page so many times before. By using story to discuss moral lessons, develop problem-solving skills, and improve comprehension, one can have a deeply meaningful conversation with the child every day. This can discover more about who the child is and what $\mathrm{s} /$ he values by asking questions about the story that indicates the importance of the stories. Young people can come up with some pretty creative solutions when given the opportunity to brainstorm with an open, accepting adult.

\section{Previous Studies}

\subsection{Riley and Burrell( (2007)}

This study discussed a micro-study within an intervention project ('Tell Me') conducted in four London primary schools, to enhance the spoken language skills of children. There were 60 children in each of the intervention and comparison groups. The focus here was to explore a classroom assessment of young children's oral narrative skills. Effective early language and literacy teaching with children from diverse backgrounds depends upon having detailed knowledge of children's oral skills, especially oral narrative skills, since the ability to narrate and report is a vital skill for future academic success and is highly correlated with later fluency in reading. Teachers needed detailed descriptions of their pupils' spoken language skills and this is especially important as populations were different. A story retelling activity, give teachers information about their pupils' language skills on entry to school. This procedure ('Tell Me') can be used in the normal course of classroom teaching.

\subsection{King (2007)}

King discovered that stories are rich sources of wisdom, imagination, creativity, and comfort. In this essay, King described her personal experiences developing and using the collaborative story making process with young people and adults in various school settings. The author stated that collaborative story making established opportunities for students to create stories from stories, using image making and abstract prompts. She maintained that the iterative process expands and improves students. oral and written expression. King invited other educators to include collaborative story making in their instructional repertoire to stimulate their own and their students. reading, writing, and speaking and 
listening skills, and to foster a supportive learning community.

\subsection{Poveda and Cuevas(2008)}

The researcher stated in this article that telling stories to children has been the focus of much research conducted mostly in schools and families while other settings where these practices also take place have been ignored. This article presents an analysis of storytelling events for children in three urban informal contexts: a library, a park and a children's bookstore in the city of Madrid (Spain). The study has a multi-method qualitative design and includes observation, audio and video recordings, documentary materials and interviews. In our analysis, these events are considered as occasions for literature socialization and this paper focuses on exposure to different literary voices as one aspect of literary language learning. To do so a comprehensive model of different narrative voices displayed by storytellers is proposed. This model is used to uncover differences across the three settings and through a case analysis for each context the types of interactions children in the audience have with these voices are examined. The discussion centers on the distinct contribution that participating in these settings may make to children's literacy learning.

\subsection{Commeyras \& $\mathrm{Hu}(2008)$}

The researchers designed a study that is a case study aimed to investigate the development of a 5-year-old child's language and literacy development in English and Chinese within a 10-week tutoring context.The primary materials were wordless picture books based on story content. As for the procedure, Storytelling in English and Chinese were the primary activities in each session. Extended activities included labeling, sentence making, and invented spelling. Data were analyzed to examine the child's development in alphabet and character recognition, oral reading and vocabulary in English and Chinese. Results indicated that wordless picture books based on story content and combined with the extended literacy activities facilitated the child's language learning in both the languages.

\subsection{O'malley et al. (2009)}

Listening comprehension is viewed theoretically as an active process in which individuals focus on selected aspects of aural input, construct meaning from passages, and relate what they hear to existing knowledge. This theoretical view has not been sufficiently supported by direct research which clarifies what listeners actually do while engaged in listening tasks. This study focused on the mental processes second language learners use in listening comprehension, the strategies they use in different phases of comprehension, and the differences in strategy use between students designated by their teachers as effective and ineffective listeners. The students in this study were all from Hispanic backgrounds, intermediate in English proficiency, and were enrolled in ESL classes at the secondary level. Findings indicated that mental processes students use in listening comprehension paralleled three theoretically derived phases of the comprehension process: perceptual processing, parsing, and utilization. Each phase was characterized by active processing and by the use of learning strategies. Three predominant strategies which differentiated effective from ineffective listeners were self monitoring, elaboration, and inference. The findings were related to implications for instructional practice.

\subsection{Barzaq (2009)}

This study is about an action research that is related to storytelling technique, the researcher points out that this style has a great effect on sequential thinking, additionally, this study investigates the possibilities of enhancing the students' achievement by practicing the sequential thinking process by using the storytelling technique, the main purpose of the study is ; to examine the questions of extent and quality of storytelling designed to stimulate the children in primary low basic graders, to determine whether the principles underlying this approach can he help produce improvement in action learning and professional development. She considered that this technique is a uniquely powerful linguistic and psychological one in the hands of a language teacher, the main question of this study is: Does sequential thinking as a storytelling form empower the English language learners ? the supplementary questions are as follows :- why are stories important ?why tell stories in class? what are the best activities related to telling a story to have the maximum impact ? how can storytelling activities develop critical thinking and creativity ? In the finding in this study, the researcher found that storytelling that are imaginative and express a wonderful style an important role in language development, telling stories to children can motivate them to read more. Also, listening to storytelling created transactional experiences that increased their knowledge. Storytelling experiences connected the students to schools by participating as listeners was an important act of negotiation and diplomacy, after discussion the researcher concluded that children will be familiar to main element of the story that enhances their study skills and they can recognize the elements of any learning text of knowledge, stories introduce students to all aspects of new language either rhythm, vocabulary, the grammatical structures or the meaningful utterance.Stories create authentic worlds in the classroom. They also increase entertainment and enjoyment in the classroom environment. She added that students retell the stories they can get new language with a real purpose. Stories can give coherence to a sequence of teaching activities, stories can make a bridge between the students and their interest, concern and learning needs.

\section{6. $\operatorname{Lin}(2010)$}

The researcher investigated whether the retelling technique can enhance English comprehension among L2 readers. The population was 126 Chinese students from a Tai- 
wanese university. Sixty five students were assigned to the experimental group and61 to the control group. Both groups received the same learning content, but the technique differed; the experimental group had the retelling technique, while the control group had conventional techniques. All participants took reading comprehension pre- and post-tests, as well as a reading comprehension strategy questionnaire. The experimental group also wrote self-reports to describe their perceptions of using the retelling technique. The results show that retelling significantly improved the participants. text comprehension at the level of overall meaning. It also helped them to learn general concepts during reading and to retain a synopsis of the story in their memory after reading. The participants using retelling could distinguish better than control participants between overall and specific ideas. They also performed better in drawing connections between pieces of information introduced at different parts of the text. However, retelling did not improve the ability of participants to remember details of expository texts. Based on these results, the study made recommendations to integrate retelling in $\mathrm{L} 2$ reading comprehension instruction.

\subsection{Hentihu (2010)}

This study is titled by " listening comprehension ", in this study, the researcher discussed listening process and considered it as one of the most challenging skills for English second language learners to develop as it is probably the least explicit of the four skills. Recently, listening comprehension has attracted the least attention among four language skills. Audio lingual courses give the impression that teachers are teaching listening when in fact they are teaching other skills. Listening teachers frequently face these three problems in teaching and learning English foreign language listening: lack of authentic listening input, absence of strategies in listening, and lack of materials. , the statement of the problem is stated in the following questions: How do the teachers select the instructional materials in teaching Listening? How do the teachers conduct the Listening activities? How do the teachers assess affectively the students in the process of teaching Listening? The objectives of the study is , the instructional materials selection by the English teachers in teaching Listening, the instructional activities conducted by the English teachers in teaching Listening, the way the English teachers assess the students in the process of teaching Listening. The significant of the study is for English teachers, the finding of this study will give valuable and useful information on the implementation of the teaching of listening. The finding can be used for a model of an ideal listening class to be implemented in their teaching. For the students, the result of the study will give impact to the improvement of the learning quality in listening. In the scope and the limitations, he stated that , teaching is a process consisting of three main components which cannot be separated from one another: objectives , implementation and the evaluation. In the literature review the researcher discussed the nature of listening, listening comprehension, factors affecting listening comprehension,types of listening comprehension activities, skills in listening comprehension, teaching listening, procedures in teaching listening comprehension, pre- , while- and post listening activity, teachers. strategies in teaching listening comprehension, he illustrated depending on many previous Studies. As instrumentation, the researcher used observation sheet, interview guide, field notes and cassette recorder, the researcher selected, transcribed and organized those raw data by referring to the formulation of the research problem. In this study the researcher suggested some tasks : pre-, while and post listening tasks. The researcher stated some listening problem : speakers speak too fast, listeners listen word for word. Listeners lack cultural or background knowledge. Speakers use too many unfamiliar words. Listening takes too much effort and concentration. Recordings are not always clear and are difficult to follow. Speaker's accents are unfamiliar. Tasks are too difficult. Listeners cannot recognize words they know when they hear them. The researcher mentioned some factors that affected the listening difficulty as follows : Listener's linguistic knowledge, Knowledge of the co-text (what went before it), Background knowledge , Learner's motivation and interest in the topic.Cognitive load of the text topic, text length, text type , Lexical density.ratio of new words to known words. The researcher also determined the approaches of listening as firstly : top-down means using our prior knowledge and experiences; we know certain things about certain topics and situations and use that information to understand. And secondly, bottom-up processing means using the information we have about sounds, word meanings, and discourse markers like first, then and after that to assemble our understanding of what we read or hear one step at a time. The researcher specified the listening strategies as :listening for main ideas, listening for details and listening to make inferences.

\section{Methodology}

The purpose of this study was to investigate the perceptions of using storytelling technique by English teachers in Gaza Governorates and the difficulties they face.

\subsection{Type of Research Methodology}

The descriptive analytical methodology was adopted to describe and analyze the information taken from the interviews to explore the teachers' perceptions. The descriptive research is defined as "A research that describes group of characteristics or behaviors in numerical terms" (Brown and Rodgers, 2002:117). Descriptive research also interprets data in words in case of qualitative data (Maykut and Morehouse, 1994). In this study, the researcher used qualitative data that was taken from the interviews.

\subsection{Research Variables}

A) Independent variables:age, gender, academic qualification, and experience.

B) Dependent variables: using storytelling technique: 
teachers' perceptions and difficulties.

\subsection{The Population}

The population of the study consisted of all UNRWA and public English language teachers and who worked in southern Gaza during the first term of the scholastic year (2012-2013).

\subsection{The sample of the Study}

First, the sample of the study consisted of (60) teachers with percent $(71.42 \%)$ who were randomly chosen as a simple random sample from UNRWA and public English language teachers who work in the southern Gaza. Tables (1,2,3 and 4) show the distribution of the ,sample according to gender, academic qualification, num, ber of working experience years, and age respectively.

Table 1. The distribution of the sample according to gender.

\begin{tabular}{ll}
\hline Classification & Number \\
\hline Male & 25 \\
Female & 35 \\
Total & 60 \\
\hline
\end{tabular}

Table 2. The distribution of the sample according to academic qualification.

\begin{tabular}{ll}
\hline Classification & Number \\
\hline Diploma & 0 \\
B.A & 52 \\
M.ED & 8 \\
Total & 60 \\
\hline
\end{tabular}

Table 3. The distribution of the sample according to number of working experience years.

\begin{tabular}{ll}
\hline Classification & Number \\
\hline $1-5$ years & 27 \\
5- 10 years & 33 \\
Up to 10 years & 0 \\
Total & 60 \\
\hline
\end{tabular}

Table 4. The distribution of the sample according to institution.

\begin{tabular}{ll}
\hline Classification & Number \\
\hline UNRWA & 24 \\
PUBLIC schools & 36 \\
Total & 60 \\
\hline
\end{tabular}

\subsection{The Instrumentation}

\subsubsection{The Interview}

The researcher interviewed 60 teachers to investigate the teachers' perceptions of using storytelling technique and the difficulties they face. The use of the interview is very advantageous as the researcher believes interviews help in revealing facts that cannot be obtained in written form as people are more willing to speak than write on a paper.

\subsubsection{Description of the Interview}

Questions in the interviews were open-ended. Following is a description of question of the interview:

Question I: was concerned with the English teachers' perception about the definition of storytelling technique and it was stated as follows:

\section{What's story telling? 1.}

Question II: was related with the English teachers' perception about the use of storytelling technique and it was stated as follows:

Do you use story telling in your teaching ? 2 .

Question III: was concerned with the English teachers' perception about the advantages of storytelling technique and it was stated as follows:

\section{What are the merits of this technique ? 3 .}

Question IV: was concerned with the teachers' perception about the characteristics of storytelling technique and it was stated as follows:

What are the characteristics of a good story telling technique ? 4.

Question V: was related to the English teachers' difficulties in using storytelling technique in education and it was stated as follows:

What are the difficulties of using story telling technique 5.

\subsubsection{Validity and Reliability of the Interview}

Since the interview has not been used before, the researcher tested it through a pilot study of twenty teachers to check its reliability. Twenty teachers were interviewed as a pilot study. The Twenty teachers were English language teachers and they were distributed according to their age, years of experience, gender and qualification. They, therefore, represent the actual sample of the study. Thus, the interviews proved gathering information about the same topic over similar group of respondents and so proved reliable (Cohen, Manion, and Morrison, 2010). The twenty teachers were excluded from the interview sample to avoid biased responses. Their responses revealed some questions did not promote open answers. They complained the interview was long and somehow boring. Therefore, the researcher modified the interview questions to be open questions. In addition, some questions were deleted, and some others were modified so that the interview estimated time became reasonable.

For validity, the interview was proved valid through referee validity as a panel of referees checked the relevance of the questions, and then the interview was modified according to the referees' notes.

\subsubsection{Developing the Interview}

When developing the interview questions, the researcher read several different previous studies related to the topic as a first step. Then, the first draft was printed out and was given to a panel of referees to ensure referee validity. After 
that, the interview was modified according to the referees' notes. Next, the interview questions were administered on the pilot sample. Finally, the interview questions were administered on the sample of the study.

\subsubsection{Conducting the Interview}

It was not an easy job to conduct the interviews with busy teachers at UNRWA and Public schools. The researcher had to carry them out amid the many working responsibilities that the researcher had too. After greeting the interviewee and thanking him or her for participating, the researcher explained the purpose of the research and its significance. Interviews were in English. Each interview took around 25 to 40 minutes. The interviews were conducted to teachers during the English language. Each teacher was noted a day before the interview day. The interviews were recorded through note-taking.

\section{Results}

\subsection{Data Analysis}

This study aims at investigating the perceptions of using storytelling technique by English teachers in Gaza Governorates and the difficulties they face. The teachers were classified into groups according to their gender, qualifications, institution and years of experience. To achieve the aim of this study, the researcher conducted an interview with the teachers according to their institution, UNRWA or Publicteachers, in addition to their qualifications,BA or MA teachers, Moreover totheir gender, female or male teachers, and to their year of experience, 1-5 years or 5-10 years.

\subsubsection{The First Study Question}

1- What are the perceptions of storytelling technique in teaching English in Palestine?

In order to answer this question, the interview had five questions, the first four questions answer the current study question which are stated as follows:

What's story telling? 1.

Do you use story telling in your teaching ? 2 .

What are the merits of this technique? 3.

What are the characteristics of a good story telling technique ? 4.

The researcher interviewed 60 teachers to explore their perceptions about storytelling technique.The interview revealed that the teachers' responses were different according to their institution, gender, qualification and years of experience.

Here are some of the teachers' answers to the interview questions:

What's story telling? 1 .

UNRWA male teachers who have an experience from 1 -5 years:

1- BA holder: using stories to express and convey messages to students with interaction in a narrative way.

2- BA holder: it's an amusing way to tell stories to children with an interactive method.
3- BA holder: it is a technique used to teach evens and historical stories.

UNRWA male teachers who have an experience from 5 - 10 years:

1- BA holder: it is used to convey some actions through words, images and sounds.

2- BA holder:it is a good technique with which I use drama to tell stories.

3- BA holder: it is an active technique in teaching English in simple and interesting way

UNRWA female teachers who have an experience from 1 - 5 years:

1- BA holder: storytelling is the art in which a teacher conveys a message truth or information, knowledge on wisdom on an audience students.

2- BA holder: It's using your own words to explain tasks.

3- BA holder: It's a process for sharing interpreting, offering the content and meaning of a story to an audience.

UNRWA female teachers who have an experience from 5 - 10 years:

1- BA holder: It's to produce new vocabulary to express ideas and feelings.

2- BA holder: It's a role play, acting and taking roles in a story

3- MA holder: It's a method or a technique in which we tackle the events of the story in an attraction way.

Public male teachers who have an experience from 1 5 years:

1- BA holder: it can encourage students to explore their unique experiences.

2- BA holder: it heightens students' ability to communicate thoughts and feelings in an articulation.

3- BA holder: it's a narrative of real or unreal events , written or narrated by someone.

Public male teachers who have an experience from 5 10 years:

1- BA holder: it is an educational technique in which teachers begin a story and let students add sentences.

2- BA holder:it is a way of teaching in which the teacher uses a funny and suspense in conveying his lesson.

3- BA holder: it is a technique to tell a story for students

Public female teachers who have an experience from 1 -5 years:

1- BA holder: it is a technique use by teachers to facilitate any story being taught.

2- BA holder: it is a way used by the teacher to make students more suspense.

3- BA holder: it is a method used by teachers to reconstruct the story.

Public female teachers who have an experience from 5 - 10 years:

1- BA holder: it is a way used by teachers in classroom to retell the story by students.

2- BA holder: it is a technique used within the classroom to convey a message.

3- MA holder: it is an art for and interaction between the teller and the sutdents to teach and delight them. 
Do you use story telling in your teaching ? 2.

UNRWA male teachers who have an experience from 1 -5 years:

1- BA holder: Sometimes

2- BA holder: Sometimes

3- MA holder: Sometimes

UNRWA male teachers who have an experience from 5 - 10 years:

1- BA holder: Sometimes

2- BA holder: Sometimes

3- MA holder: Sometimes

UNRWA female teachers who have an experience from 1 - 5 years:

1- BA holder: Sometimes

2- BA holder: Sometimes

3- MA holder: Sometimes

UNRWA female teachers who have an experience from 5 - 10 years:

1- BA holder: Sometimes

2- BA holder: Sometimes

3- MA holder: Sometimes

Public male teachers who have an experience from 1 5 years:
1- BA holder: Sometimes
2- BA holder: Sometimes
3- MA holder: Sometimes

Public male teachers who have an experience from 5 - 10 years:

1- BA holder:rarely.

2- BA holder: Sometimes

3- MA holder: Sometimes

Public female teachers who have an experience from 1 -5 years:

1- BA holder: Sometimes

2- BA holder: Sometimes

3- MA holder: Sometimes

Public female teachers who have an experience from 5

- 10 years:

1- BA holder: Sometimes

2- BA holder: Sometimes

3- MA holder: Sometimes

What are the merits of this technique ? 3.

UNRWA male teachers who have an experience from 1 -5 years:

1- BA holder:maintaining the interest of students.

2- BA holder:helps students to memorize their lesson

3- MA holder: it attracts students.

UNRWA male teachers who have an experience from 5 - 10 years:

1- BA holder: attractive

2- BA holder: makes them happy

3- MA holder: it enriches students' vocabulary.

UNRWA female teachers who have an experience from 1 - 5 years:

1- BA holder:The merits of storytelling is to encourage cooperation between students and use imagination.
2- MA holder: It simplifies the lessons.

3-MA holder: It makes students happy.

UNRWA female teachers who have an experience from 5 - 10 years:

1- MA holder: It's a way to amuse students.

2- BA holder: students can learn morals.

3- MA holder: it can support daily life skills.

Public male teachers who have an experience from 1 5 years:

1- BA holder: it helps students solve problems

2- BA holder: it attracts them

3- MA holder: it helps them predict what is coming next.

Public male teachers who have an experience from 5 10 years:

1- BA holder:enhance listening skills

2- MA holder: increase motivation

3- MA holder: it encourages cooperation

Public female teachers who have an experience from 1 -5 years:

1- BA holder: encourages participation.

2- BA holder: it attracts students attention

3- MA holder: it helps students memorize the story

Public female teachers who have an experience from 5 -10 years:

1- BA holder:it simplifies the lesson

2- BA holder: it makes students happy.

3- MA holder:it attracts their attention

What are the characteristics of a good story telling technique ? 4.

UNRWA male teachers who have an experience from 1 -5 years:

1- BA holder: it must be related to the subject ideas.

2- BA holder: it should suit the students' level

3- MA holder: it should suit the students' culture.

UNRWA male teachers who have an experience from 5 - 10 years:

1- BA holder: have a goal

2- BA holder: subjective

3- MA holder: encouraging

UNRWA female teachers who have an experience from 1 - 5 years:

1- BA holder: storytelling should be: related to the aim of the lesson, have beginning and end, include body language facial expressions.

2- BA holder: It should concentrate on the main aim of the lesson.

3- MA holder: Gaining verbal skills and clear communication and wisdom.

UNRWA female teachers who have an experience from 5 - 10years:

1- BA holder: gaining verbal skills.

2- BA holder: imagination

3- MA holder: morals and cooperation.

Public male teachers who have an experience from 1 5 years:

1- BA holder: suits students' age

2- BA holder: suits students' level 
3- MA holder: have an aim.

Public male teachers who have an experience from 5 10 years:

1- BA holder: clear

2- BA holder: timed

3- MA holder: suits the students' level.

Public female teachers who have an experience from 1 -5 years:

1- BA holder: it should follow the Ministry education guideline.

2- BA holder: suits the age of students

3- MA holder: suits the level of students.

Public female teachers who have an experience from 5 - 10 years:

1- BA holder: care about low achievers

2- BA holder: have an aim

3- MA holder: well timed.

To answer the second question of the study which is stated as follows:

2- What are the difficulties facing English language teachers in using storytelling technique?

The interview fifth question was concerned to answer this study question and it was stated as follows:

What are the difficulties of using story telling technique ? 5.

The answers were different from one participant to another. The following lines are the answers of some participants according to their institution, gender, years of experience and qualifications.

UNRWA male teachers who have an experience from 1 -5 years:

1- BA holder: individual differences may be neglected.

2- BA holder: this may cause noise.

3- MA holder: there is lack of materials.

UNRWA male teachers who have an experience from 5 - 10 years:

1-BA holder: students misunderstand the aim of the story.

2- BA holder: it can't be used with all the levels of students.

3- BA holder: it causes noise.

UNRWA female teachers who have an experience from 1 - 5 years:

1-BA holder: many students may miss the connection between different parts of the story.

2-BA holder: neglecting weak students.

3-MA holder: I need a lot of time.

UNRWA female teachers who have an experience from 5 - 10years:

1- BA holder: grammatical errors

2- BA holder: it's noisy

3- BA holder: managing classroom troubles.

Public male teachers who have an experience from 1 5 years:

1-BA holder: it needs a lot of time

2- BA holder: it's noisy

3- MA holder: ignoring low achievers.

Public male teachers who have an experience from 5 -
10 years:

1- BA holder: noisy

2- BA holder: lack of time

3- MA holder: neglecting weak students.

Public female teachers who have an experience from 1 -5 years:

1- BA holder: the time is so limited.

2- BA holder: the guideline of the ministry of education doesn't have this technique.

3-MA holder: the culture of students may cause troubles.

Public female teachers who have an experience from 5 - 10 years:

1- BA holder: wasting time

2- BA holder: noise

3- MA holder: difficult to use

\section{Discussion}

After reviewing all the responses of all teachers relating to their gender, years of experience, institution and qualification we find that their answers were different and that means they have no clear information about the storytelling technique. Concerning the first questions: "What's story telling?", it was clear that most of the teachers didn't know the right definition of the storytelling technique, this may be attributed to the lack of training for novice and in-service teachers. In addition, This indicates that even if teachers technique, they didn't know how to deal with its educational process.

Regarding the second question:" Do you use story telling in your teaching?", All the teachers' responses were similar as they use the storytelling technique SOMETIMES.

Additionally, the third question:" What are the merits of this technique?"

was easy for teachers regardless the different variables. As their responses were similar sometimes.

Concerning the fourth question: "What are the characteristics of a good story telling technique ?" the responses of the teachers regardless all the variable were similar most of the time.

Regarding the second question which is stated as follows: What are the difficulties of using story telling technique ? 5.

After reviewing all the responses of the interviewees, the researcher noticed that they have real difficulties when using this technique, sometimes because of the lack of time or because of the noise inside the class. This may be attributed to the lack of knowledge and training of this technique.

\section{Conclusion}

Storytelling is an approach that worth pursuing in teaching English as foreign language classes in the Palestinian context. Learners' ability to get the gist ,to recognize characters and to summarize what they listen to through the storytelling technique is important. Class environment change from a dry boring one to a warm environment full of 
students concentration, participation and production by using the storytelling technique.The researcher tried to investigate the use of storytelling technique from the teachers' perspectives all over Gaza Governorates and the difficulties they face. By reviewing the empirical previous studies which investigated the effect of storytelling technique on the learning-teaching process, The researcher has reached the following points and the findings related to storytelling technique :

- It had the superiority over the traditional method in teaching listening comprehension.

- It provided the learners with a better learning environment which reflected on their scores.

- It was very effective in motivating the learners towards participation and interaction

- It provided the learners with enjoyment and pleasure that affect their achievement positively.

- It is an excellent teaching technique because it evokes students' interest, help

students create vivid mental images and stories activate the thinking process.

- It connects events and concepts that help students better understand and later recall information.

- Opening a lesson with a story may put the students at ease and allow them to understand something concrete before going on to the related abstract concept.

- Depending on the age of the students, storytelling can be used in almost any subject area such as, English and history.

- Traditional storytelling has been used to share traditions and entertainment in different generations.

- Students can get involved and can even participate in class stories.

- Storytelling is an excellent means of introducing children to the wonderful world of books while building positive attitudes for reading. The exposure to oral language patterns helps developing children's listening sub-skills.

- Storytelling allows the child to create images in his or her imagination, it evokes the students' imagination, listening to story encourages students to use their imaginations that empowers students to consider new ideas. As a result it builds self-confidence and personal motivation.

- Storytelling can change the difficult ideas into easy ones and make the abstract language, teachable one.

- Storytelling provides the context in which knowledge arises, hence it becomes the normal vehicle for accurate knowledge transfer.

In this study, results of the interviews showed that teachers lack knowledge about the use of this technique regardless their gender, institution, qualifications and years of experience. In addition, they really face difficulties which get them ignore the use of this technique.

\section{Recommendations}

The researcher recommends syllabus designers to provide the Palestinian syllabus with different stories that enhances many skills of English language. Additionally, he recom- mends Supervisors to rework the Palestinian curricula and increase the listening material to include the art of storytelling, and to prepare and distribute instructional materials that increase teachers' awareness of storytelling technique significance and the necessity of using this strategy in teaching English. Moreover, English language teachers are recommended to move from the traditional method in teaching listening into new modern techniques, such as, storytelling technique that creates a new learning environment.

Recommendations for further studies

- The Palestinian Ministry of Education should conduct further researches to investigate the effectiveness of similar programs at different levels of education in Palestine.

- Further studies should be conducted to investigate the strategies and techniques employed by teachers in Gaza schools.

\section{References}

[1] Barzaq.M.( 2009)Integrating Sequential Thinking Thought Teaching Stories in the Curriculum.Action Research.Al.Qattan Center for Educational Research and Development QCERD. Gaza.

[2] Belmonte, I.A and Verdugo, D.R (2007). Using Digital Stories To Improve Listening Comprehension With Spanish Young Learners Of English.

[3] Craig, S., Hull, K., Haggart, A. \& Crowder, E. (2001). Storytelling: Addressing the literacy needs of diverse learners. The council for exceptional children, 33(5), 44-51.

[4] Commeyras, M. and Hu, R.(2008)"A Case Study: Emergent Biliteracy in English and Chinese of a 5-Year-Old Chinese Child with Wordless Picture Books" Reading Psychology,p. 1. 30 . viewed 24 .

[5] Egan, K.(1995)Narrative and learning :A voyage of implications :Teachers College Press.

[6] Green, M. \& Brock, T. (2000). The role of transportation in the persuasiveness of public narratives. Journal of Personality and Social Psychology, 79, 401-421.

[7] Green, M.(2004) Storytelling in Teaching. The Association for Psychological Science April 2004 Volume 17, Number 4.

[8] Hentihu , I.K (2010) Listening comprehension. The Teaching of Listening at Faculty of Letter State University of Malang Thesis Proposal.

[9] King, N. (2007)"Developing Imagination, Creativity, and Literacy through Collaborative Storymaking: A Way of Knowing". Harvard Educational Reviewed77, 2, p.204-227.

[10] Lin,L.F. (2010) The Impact of the Retelling Technique on Chinese Students. English Reading Comprehension.National Taiwan Ocean University Taiwan Australian Journal of Early Childhood Australian Inc,vol.25\& 12, Issue 2 no.3, p.1-5.

[11] McDrury, J., \& Alterio, M. (2003). Learning through storytelling in higher education. Sterling, VA: Kogan Page Limited.

[12] Mello, R. (2001). The power of storytelling: How oral narrative influences children's relationships in classrooms. In- 
ternational Journal of Education and the Arts. 2(1).

[13] Niemann, H. (2003), Learning English through story books. Retrieved December 12, 2012 from http:// www www.eltforum.com/

[14] O'MALLEY.J.M , CHAMOT.A.U, and KÜPPER,L (2009) Listening Comprehension Strategies in Second Language Acquisition Georgetown University, InterAmerica Research Associates , Interstate Research Associates.Oxford University Press.

[15] Parr, M. \& Campbell, T. (2007). Teaching the language arts: Engaging literacy practices. Toronto, ON: Wiley \& Sons.

[16] Pellowski A. (1990) The world of storytelling. Expended and revised edition. A practical guide.

[17] Poveda, D.I. and Cuevas, I. (2008)"Literacy voices in interaction in urban Storytelling events for children". Linguistics \& Education. 19, 1, p37-55.

[18] Reilly R. ( 2007 ) STORYTELLING: PATHWAY TO LITERACY. Unpublished M. Ed. thesis. The Evergreen State College

[19] Shelly.J. (2010) Read it again please! The importance of story time. Available in: http://www.awakeparent.com

[20] Wojciechowicz, L. (2003). The power of storytelling: 8 reasons for infusing storytelling into your curriculum. South Mountain Community College Storytelling Institute. 